\title{
Upfront
}

\section{Guest Editorial: Interrogating Shared Societies Through Practice and Theory}

\author{
CLEM MCCARTNEY
}

'Shared Vision'; 'Shared Future'; 'Shared Space': it seems the word 'Shared' is becoming commonplace in the language that is being used to talk about national building, intercommunity relations and peace building. Even the protagonists in inter-group conflict are using the word. And now we have a Shared Societies edition of Development.

When the Club de Madrid started to use the phrase 'Shared Societies' in 2007, it was less commonly heard, and the Members are heartened that it has become part of the discourse and seems to resonate with many people, including political leaders, activists, international organizations and members of different ethnic groups. At that time, the Club de Madrid was interested in how to overcome social conflict and inter-group tension and violence. It is an organization of democratically elected former presidents and prime ministers (over 90 at the last count) and they want to make their experience and expertise available to current leaders facing the major challenges of today. And intergroup tension and conflict is certainly a major challenge. Identity is becoming more and more salient as other certainties are eroded and is at some level an element in most conflicts around the world. Social conflict holds back development, or it is patchy and uneven with some groups benefiting and other groups left behind. Many local communities function badly and residents are uncomfortable, if not fearful, because of tensions between identity groups. Very few countries in the world are homogeneous, and with increasing flows of migrants within and between countries these tensions are likely to increase.

But if it is easy to recognize a divided society and the resulting problems, it is much more difficult to describe a society that is at peace with itself and even more difficult to identify how it can be achieved. The Club de Madrid wanted to use a language that could encapsulate a concept that would help societies to see their way to move forward to fair and equitable social relations between people living in the same territory. The language at that time was about 'integration' and 'inclusion'. Do these words express this concept? Sometimes they are used in that way, but they also could have the connotation that one group or community (usually the weaker) had to be absorbed into, integrated and included into an existing group (usually the stronger). But that does not work. As one member of the Club de Madrid, Jenny Shipley, has said " "you have to be like us" is an unintelligent and unsustainable approach'. 


\section{McCartney: Guest Editorial}

At the same time, the idea of multiculturalism was coming under scrutiny, especially in Europe where a number of countries had adopted an approach that respected difference and diversity and facilitated immigrants to maintain the cultures and practices of their identity group and place of origin. That seemed to lead to separate existence. We need to find a third way other than on the one hand assimilation, which leaves the weaker group resentful that their identity has not been truly recognized and respected, and on the other hand multiculturalism, which, if it becomes separate existence, leaves the dominant group resentful and confused by the presence of a group or groups that do not seem to want to integrate and that pursue life styles and practices they do not understand and perhaps resent.

We need a basis for inter-group relations that gives the sense that we are all different but in a common project to build a society which benefits us all and which requires us all to contribute to make that happen - a Shared Society. A Shared Society is not owned by one section of the community but belongs to everyone. It is an active form of sharing that goes beyond tolerance and co-existence. If governments and the dominant sectors of society recognize the desire of individuals to belong and fulfil their ambitions even if they seem different from other sectors of society, and if they make spaces for individuals to pursue their personal ambitions in their own way, and at the same time give them the support they need, then there is a strong motivation and incentive to integrate into the rest of society. Those aspects of their identity, such as language, religion, clothes and other cultural practices that mark them out as different, do not disappear, but become a matter of personal expression and not a statement of difference. They are nevertheless important because they strengthen their personal sense of ease and wellbeing, as is already the experience of the rest of society. A virtuous circle emerges because when an individual or group feels they belong and are valued, then they are willing to reach out and meet their neighbours and help to strengthen the society.

These aspirations can, however, be easily blocked if there is no encouragement of a Shared
Society and as a result a vicious cycle develops, instead of the virtuous cycle to which we aspire.

The Club de Madrid not only adopted the term Shared Societies, but was also ready to engage with current leaders and activists as they faced these challenges at local, national, regional and global levels and established the Shared Societies Project, thanks to the ongoing support of the Alan B. Slifka Foundation. It was initially convenient that the term was unfamiliar because one could not jump to the conclusion that everyone was referring to the same idea. Everyone is in favour of harmony and peace and stability but it is important to check what that means for them and how they are to be achieved.

As former political leaders, the Members of the Club de Madrid are well placed to engage with and, from their own experience, can help current leaders to analyse the challenges they face and their options for meeting those challenges. As former leaders they are readily received by people at all levels and have the convening power to bring diverse groups together. Being now out of office, they do not represent any state or special interest beyond the overall commitment of the Club de Madrid to democracy and good governance, and so are seen as non-threatening. The Members know the opposition that political leaders face if they wish to initiate change, not least from their own supporters. They know the loneliness of office and current leaders find their support helpful and impartial.

But they also need to be informed about the issues and be able to raise questions and make comments that are appropriate and relevant. And while all the members are different, coming from different cultures and from different points on the political spectrum, they also want to represent a common Club de Madrid analysis. For these reasons the Club de Madrid articulated the vision of a Shared Society, its underlying principles and ideas on how one got there.

This concept and the resulting project materials are referred to in many of the articles in this edition of the journal. The original documents can be easily accessed on the Club de Madrid website (http://www.clubmadrid.org/en/programa/the shared_societies_project). It was agreed that the 
concept is underpinned by four key principles: respect for the dignity of the individual and his or her community, absence of discrimination, protection of his or her human rights, and the opportunity to participate, ideally, but not exclusively, through a democratic process.

It was also agreed to focus on ten aspects of policy and inter-group relations that are key to achieving a Shared Society. We called them the Ten Commitments (see Box 1) because political leaders and the community as a whole need to be committed to assessing how far they are positively addressed in their society and work on strengthening them if necessary. The project does not say what you should do in relation to each of the Commitments, so in that sense it is not

Box 1. The ten Commitments for a shared society

\section{COMMITMENT I}

Locate responsibility to ensure the promotion of social cohesion clearly within government structures.

\section{COMMITMENT II}

Create opportunities for minorities and marginalised groups and communities to be consulted about their needs and their perception of the responsiveness of state and community structures to meet those needs.

\section{COMMITMENT III}

Ensure that social cohesion is considered in devising governance structures, policy formation and policy implementation and establish procedures and mechanisms to ensure this is achieved and to reconcile divergent positions between sectional interests.

\section{COMMITMENT IV}

Ensure the legal framework protects the rights of the individual and prohibits discrimination based on ethnic, religious, gender or cultural difference.

\section{COMMITMENT V}

Take steps to deal with economic disadvantages faced by sections of society who are discriminated against, and ensure equal access to opportunities and resources.

\section{COMMITMENT VI}

Ensure that physical environments create opportunities for, rather than discourage, social interaction.

\section{COMMITMENT VII}

Ensure an education system that offers equal opportunity for developing the knowledge, skills, capacities and networks necessary for children to become productive, engaged members of society and that demonstrates a commitment to a shared society and educates children to understand and respect others.

\section{COMMITMENT VIII}

Initiate a process to encourage the creation of a shared vision of society at local and national level.

\section{COMMITMENT IX}

Promote respect, understanding and appreciation of cultural, religious and ethnic diversity and support local communities in exploring their identity, sharing their experiences with other identity groups and working together with those groups on common concerns.

\section{COMMITMENT X}

Take steps to reduce tensions and hostility between communities and ensure members of all communities are protected from abuse, intimidation and violence. 


\section{McCartney: Guest Editorial}

prescriptive, but it is clear that they are all necessary in building a Shared Society. Many leaders and communities find it easier to adopt a single strategy to overcome social divisions as if there was a golden key, but such an approach will have unintended consequences which may negate the intended outcome, and it is important to work in a balanced way across all the dimensions.

The project has listed various approaches that could be adopted under each Commitment. These are approaches which have been implemented in various countries under various conditions and may be relevant to a society trying to deal with its own problems. And under each approach we give specific examples of projects and practices. It is clear from these examples that fixing relations that are broken is not solely the responsibility of government. In fact there are limitations on what governments can do, particularly when one is dealing with attitudes and relationships at local level. At the same time governments cannot deny their responsibility. They need to create an enabling environment for those individuals and organizations working on the ground with communities to avoid polarization and overcome division. For example, if there has been inter-group rioting the statements of the government must be clear and unambiguous and impartial in addressing the need to rebuild relationships, but often the government is seen as identified with one section of the society and its statements seems to criticize mainly those from other groups. This exacerbates the problem and hinders the efforts of those working on the ground.

Since 2008, the original materials of the project have proved a valuable resource for the Members of the Club de Madrid in their missions as a means to frame discussions with local activists and political leaders. For example, in one country there were differences of opinion between the executive and the legislature on framing a policy on ethnic relations following inter-communal riots. During a series of Club de Madrid missions, both papers were shared with the Members for comment and they were able to do this by comparing them with the ideas laid out in the Shared Societies Project. The examples are also drawn on when exploring future policy options. It is encouraging that they have also been used by national and local NGOs. For example, an Israeli organization has translated some of the materials into Hebrew for use in their work.

At the same time the project has continued to develop its analysis of the issues and additional materials, on the basis of project activities and also through specially convened working groups. A recurring theme in the work, referred to in some of the articles in this collection, is the benefits that come from a shared society. It is important because it is fair and just that all people in the society feel they belong and have equal opportunity. And everyone benefits and feels more secure if they have good relationships with other identity groups, either in their own neighbourhood or in other parts of the country. I noted at the beginning of this paper some of the problems that arise from inter-group tension and conflict. In addition there is evidence, which a number of authors refer to in their articles, that a Shared Society, or at least a more equal society, has a positive impact on economy performance and development in general, while a divided unequal society is a drag on development. ${ }^{1}$ Therefore the project went farther, and with partners, developed 'A Global Shared Societies Agenda to Promote Long Term Sustainable Growth' (http://www.clubmadrid.org/img/ ssp_secciones/GSSA_31082012.pdf) and has argued that Shared Societies are the necessary foundation for achieving the Sustainable Development Goals and so far that perspective seems to be underpinning the draft goals.

This connection between development and Shared Societies brings us to this Shared Society edition of Development. The Club de Madrid is delighted at this collaboration with the Society for International Development, not only because it provides an opportunity to bring the Shared Societies Concept to a wider audience, but also because it provides an opportunity to develop a dialogue with other people working on development and to push the boundaries of the concept.

We are satisfied that the concept is useful. It becomes ever more evident that the Shared Societies Concept is a valuable framing concept for work at many levels on many issues and in many situations. It provides a valuable means to engage 
with current leaders at all levels to explore relevant issues of development and to assist them in the pursuit of many desirable goals. It is also clear that people are comfortable with the term and can relate it easily to the challenges they face. This issue of Development opens up a space to consider how this idea fits with other ideas about peace, participation and inter-group relations and with experience on the ground.

The authors come from many different backgrounds: politicians, academics, practitioners and activists. While the authors do not speak on behalf of their place of origin, the articles do come from very different cultural and political frameworks. So we have articles from a society reflecting Confucian thought to one nurtured in Islam and another in Polynesian/Melanesian culture. There are contributions from large and small countries, democratic and authoritarian regimes and some in transition.

Cassam Uteem, former president of Mauritius, a very diverse nation, and Co-Chair of the Club de Madrid Working Group on Shared Societies, provides an introduction to the Shared Societies Project.

The Post-2015 Development Process is the focus of the Thematic Section, given its topicality and the relevance of the Shared Societies Concept. Danilo Türk, former President of Slovenia and former United Nations Assistant SecretaryGeneral, provides a reminder of the way in which the United Nations functions, an understanding of which is essential if one wants to influence the process. Amina Mohammed, the Secretary General's Special Adviser on the Post-2015 Process, gives an overview of the current situation and shows the relevance of a Shared Societies Perspective. Sarah Cook and Esuna Dugarova, from the United Nations Research Institute for Social Development, then look beyond 2015 and consider what will be the nature of social development in the future.

In the Dialogue Section the authors relate the Shared Societies Concept to their own work on Peace (Steve Killelea), Horizontal Inequalities (Frances Stewart) Participation (Johanna Birnir and Eric Dunford) and women's empowerment to give more weight to Inequality and Birner and Dunford explore some methodological issues and developed data that points to the positive impact of Participation on development. These are key elements of the Shared Societies Framework though embedded and interlinked with other dimensions of the concept. This does not deny the importance of these specific dimensions and it is important that they are championed. Killelea introduces the concept of Pillars of Peace, which is again a multidimensional framework, which, as he notes, is very similar to the Ten Commitments of the Shared Societies Project. Mohamed approaches the issue from a policy perspective, or more correctly from the perspective of those seeking to bring about policy change and promote a more inclusive shared society, in this case by the empowerment of women. She shows the value of intergovernmental protocols as a foundation for bringing about desired change.

In Local/Global Encounters, experience in specific contexts is described and how far, if at all, the Shared Societies Concept is relevant and useful. All the examples show some of the tensions in achieving a balanced approach which recognizes the separate identity of different groups without marginalizing them and instead encourages shared involvement in building for the future. Huang Jiansheng provides a fresh perspective on the concept by offering a critique of its application in China from a Confucian perspective. China has been stable for some time but is now facing the need to adjust to its new situation in the world and Jiansheng concludes that in many ways the Shared Societies Concept is in harmony with the Chinese concept of the Harmonious Society and can inform the development and application of that idea. The Island States of the Pacific have also been relatively stable, with some exceptions but, as Claire Slatter documents, they face many challenges in relation to inter-group relations exacerbated by migration and the challenge of climate change.

The Philippines has faced serious secessionist conflicts, perhaps indicative of earlier failures to accommodate all communities in a Shared Societies, and is now in a post-war, but not necessarily a post-conflict stage. There has recently been a 


\section{McCartney: Guest Editorial}

negotiated settlement with the Moro Islamic Liberation Front in relation to autonomy for their region Bangsamoro. Senen Bacani and Miriam Coronel Ferrer were members of the negotiating panel, Ferrer being the chair. They describe how the agreement has addressed some of the issues, particularly revenue and territory, that could facilitate progress to a new Shared Society. The achievement of a peaceful settlement is in itself an achievement, and time and the practical working out of the agreement will tell if these arrangements facilitate progress towards a new Shared Society across the Philippines or if the gap between Bangsamoro and the rest of the Philippines becomes entrenched.

The Middle East and North Africa have faced many challenges in the transition processes following the uprisings that began in 2011, and it is still unclear what the final outcome will be for many of the countries in the region. Dina Shehata makes comparisons between the different ways in which the situation has played out in each country. In the context of the present discussion, one conclusion is that the revolutions were in part caused by social exclusion and the countries that have fared best in the subsequent years are those who have been able to work towards greater inclusion, sometimes supported and sometimes frustrated by external forces. Finally Ashish Kothari not only gives a critical assessment of the situation in South Asia at present but also proposes an alternative model, radical ecological democracy bringing together inclusion and sustainability. This is an important link which has not been fully explored till now and his model not only resonates with the Shared Societies Model but complements it.

I believe that the articles in this issue provide interesting insights and they will help to think what is required to move the project to another level in terms of diffusion, engagement and impact.

\section{Note}

1 Club de Madrid, Economics of Shared Societies Madrid, 2011, Club de Madrid or http://www.clubmadrid.org/img/ secciones/The_Economics_of_Shared_Societies_Publication.pdf. 


\section{WORLD LEADERSHIP ALLIANCE \\ CLUB DE MADRID}

\section{democracy that delivers}

The Club de Madrid is the world's largest, independent group of democratic, political leaders, committed to addressing the challenges of democratic transition and consolidation there where they can make a difference.

The principal added value of the Club de Madrid is a unique membership of nearly 100 , democratically elected, former Presidents and Prime Ministers, from over 60 countries, willing and able to share their diverse expertise, experience and networks in support of democratic values and leadership worldwide. As former Presidents and Prime Ministers, no longer in public office, Club de Madrid Members are not politically constrained and thus freer to share their experience and offer strategic advice.

Drawing on the Members' experience, convening power and access, the Club de Madrid works in two key areas:

- Addressing global challenges from a democratic perspective;

- Supporting democratic transition and consolidation processes.

Our approach is practical and results-oriented, based on direct and concrete exchanges between our Members and current leaders. In this space, we work with governments, inter-governmental and civil society organizations, as well as with academia and the business sector, building bridges and fostering dialogue essential to social and political transformation.

\section{www.clubmadrid.org}

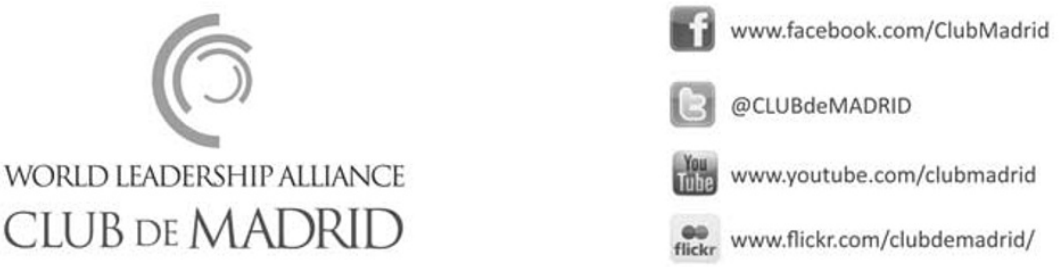

Club de Madrid

Calle Mayor, 69, Planta 1 - 28013 Madrid (Spain) - Tel. + 34911548230 - Fax. + 34911548240 clubmadrid@clubmadrid.org -www.clubmadrid.org 